\title{
L'ABBÉ GRÉGOIRE Y LAS COLONIAS FRANCESAS DEL CARIBE
}

En un Simposio Internacional dedicado a Religión e Historiografía, y más en concreto a la irrupción del pluralismo religioso en América Latina, la figura y personalidad de Henri Baptiste Grégoire es una referencia que no debe quedar tan sólo en el terreno de lo implícito. Estamos ante un hombre que ha merecido de los estudiosos y de los historiógrafos una atención de todo punto excepcional, plasmada en multitud de páginas extendidas en torno a su memoria. Él ha sido delicado e impetuoso apologista -subráyese la paradoja- del pluralismo religioso (si por tal se entiende el respeto sincero a toda convicción de conciencia), un polígrafo siempre por conocer, un investigador culto, un infatigable buscador de nuevos caminos: y todo ello, en el momento en que la Ilustración alcanzaba su máxima turgidez a punto de dar a luz a nuestra época. Las páginas que siguen, pretenden dar un boceto de aquella faz que corresponde a una de las mentes más inquietas, que puso sobre el tapete un acervo de cuestiones incitantes y reivindicó derechos humanos fundamentales.

\section{LA LLAMADA DE AMÉRICA}

Se dice -y es obvio- que el Atlántico mide la separación de sus dos alejadas riberas. Se dice también -y no es tan obvio- que el Atlántico une, como coyuntura viva, las dos tierras -la del Antiguo y la del Nuevo Continente- haciéndolas recíprocamente imprescindibles. Para los promontorios occidentales de la Vieja Europa el océano inmenso acabó presentándose como desafío - mucho más que como confín infranqueable-: en fin, ya en el siglo XVII el Atlántico había sido sendereado y para finales del XVIII había adquirido índole mediterránea. 
Así, por tanto, España y Francia -por no decir también Inglaterra o Irlanda, Holanda o los países Escandinavos- han podido hablar con insistencia de su vocación americana y han podido sentirse benefactores, Dios sabe si con razón, de sus hermanos que viven allende los mares. "iQué dignos son de vuestra confianza -exclamaban los obispos constitucionales reunidos en París en su carta a los sacerdotes y fieles de las colonias francesas-, qué dignos son de vuestra confianza los hombres generosos que van a abandonar su tierra natal, a separarse de sus amigos, a arrancarse del seno de sus familias para atravesar el vasto océano y predicaros esta divina moral! (...) ¡Qué dignos son de vuestro amor estos obreros que el Padre de familia llama a su viña, que van a recibir de Él la augusta misión de ganar almas para Jesucristo y de trabajar sin descanso para extender su heredad! ¡Cuánto derecho tienen a vuestro reconocimiento estos ángeles de paz que se encaminan a re-anudar todavía más los lazos que os unen a la Madre Patria y cuyo ministerio, en último término, concurrirá a la prosperidad incluso temporal de la metrópoli y de las colonias!»' ${ }^{1}$.

América fue descubierta y amada. No ha sido así la suerte de África. El continente africano ha sido durante siglos un gran desconocido estando tan próximo al Viejo Mundo. América, no: desde el primer momento fue vista como un logro de la audacia que la suerte ayuda. Los que desde las Columnas de Hércules o desde el cabo de San Vicente miraban sobre el mar, veían lo interminable, lo impreciso, lo aventurero. Atravesado el mar, el Nuevo Mundo siguió reclamando exploración. Tal vez ése haya su primer augurio -el de los sueños y de los mitos-. El hombre lleva en sí la necesidad de progreso. Las Américas habían sido descubiertas palmo a palmo por quienes no las conocían y sentían avidez de conocerlas. Dice Tomás de Aquino que de «los dos modos de adquirir la ciencia -a saber: investigando por sí mismo o aprendiendo de otros-, la investigación es el principal y el aprendizaje es el secundario». Y enseguida citando a Aristóteles corrobora: «Es óptimo aquel que por sí mismo llega a comprender todo; el que es dócil -aprendiendo de quien bien enseña- es simplemente bueno»².

1. Épître des évêques réunis à Paris aux pasteurs et aux fidèles des colonies françaises. [Signé: +Pierre Saurine, évêque de Dax; +Éléonore-Marie Desbois, évêque d'Amiens; +Henri Grégoire, évêque de Blois.] Donné à Paris, le 1er. Germinal, an VII de la République Française, Paris, Imprimerie-librairie chrétiénne, an VII, 71.

2. Summa Theologica, III pars, q.9, a.4 ad primum. 
A América han ido hombres europeos que se hicieron mejores allí con su entrega. En América, sin embargo, se reflejaron también -en otras ocasiones- los errores de Europa. «¿Es que no hemos encontrado aquí en Europa -se preguntaba Grégoire- el espectáculo frecuente de talentos de los más distinguidos que se envilecieron con las bajezas de la adulación y con la infamia de su conducta personal?».

Un signo de cultura consiste en la asimilación de la crítica y en la capacidad de analizarse y autoenjuiciarse reconociendo las propias limitaciones. Grégoire -antiguo obispo constitucional de Blois y portaestandarte de la Revolución- era patriota, como lo es todo francés. Pero no temía la crítica: la Revolución le había debido de acostumbrar a encajarla sin sobresalto. Tampoco temía criticar, desafiar a las grandes cabezas: sus labios habían detonado frases terribles contra la monarquía borbónica. Todo el mundo conocía - o creía conocer- su voto afirmativo condenando a Luis XVI y a María Antonieta ${ }^{3}$. En 1823, su palabra todavía conservaba -pese a los años transcurridos- aquella terrible fuerza de denuncia que le hizo célebre en los días de la Convención: «La organización de los gobiernos tiene hoy por objeto sustituir la fuerza moral por la fuerza física: es ésta la que debe subordinarse a la primera; pero desde que aquellos que fueron los dos más grandes maquinistas del tiempo moderno -me refiero a Federico II y a Bonaparte, a quienes se les dedica (prostituyendo el término) el apelativo de grandes-, desde que ellos, digo, convirtieron a miles de hombres en miles de autómatas, la bayoneta reemplazó la ley y el ruido del cañón hizo enmudecer la justicia. Muchos pueblos que fueron espirituales, amables, gigantes en la carrera tanto de las armas como de las ciencias - pigmeos, sin embargo, en el camino de la virtud- perdieron la energía de su carácter y marchan ya hacia la descomposición».

Grégoire se ufanaba como paladín de la Libertad. De ahí, su afán de brindar con licor auténtico de modernidad y no con engaños degradantes: "Haitianos, he aquí el azote que os amenaza. Azote más temible que esas fiebres contagiosas que por una invasión súbita han asolado muchas veces diversas regiones del Nuevo Mundo. (...) ...el adversario más temible para la libertad es el libertinaje; él ha introducido y, por así decirlo, ha naturalizado el concubinato desgraciando todavía hoy la mayor parte de las Antillas. Recordad que este vicio vergonzoso y humi-

3. El dato, por repetido que sea, no puede darse por probado. 
llante de por sí ha sido un funesto resultado del sistema de esclavitud. Esta consideración es un motivo más para aborrecer y abandonar sin dilación ese comercio impuro, mediante el cumplimiento de todas las formalidades requeridas por la ley.... ${ }^{4}$.

Cuando el ex-obispo constitucional de Blois escribía estas exhortaciones había acumulado ya una larga experiencia a través de amargos escarmientos. Pero se equivocaría quien se dejase impresionar creyendo que los avisos contra el libertinaje se deben a la prudencia del anciano. Henri Baptiste Grégoire había sido así desde sus años juveniles, si es que no desde su misma infancia. Y no debe extrañar. La «fille ainée de l'Eglise» ha sido fecunda en fermentos espirituales y en personalidades de encrucijada. En santos que van al infierno $o^{5}$ en grandes atormentados por la duda. Duda entre lo temporal y lo eterno, «flirteo» entre los valores de la revolución y del progreso y la permanencia del dogma y de las tradicionales virtudes del pueblo francés. Los siglos XVIII y XIX han sido ubérrimos en este tipo de experiencias humanas.

Grégoire había sido, de joven, sacerdote fogoso -si no fervoroso-. Había sido educado con la gramática de Port Royal y había hecho sus confesiones infantiles con un párroco "piadoso» de corte jansenista. La «delectatio victrix» es engañosa como las mismas sirenas. Grégoire había sentido y seguía sintiendo -y así iba a ser hasta el final, durante toda su vida- una concupiscencia superior que le llevaba al amor universal, hacia la fraternidad sin fronteras. Él no es un revolucionario «inducido»: su amor a los marginados -de la cultura, del dinero, de la raza- data de su misma madurez juvenil. Años antes de la explosión revolucionaria ya se había preocupado seriamente de los judíos y se había comenzado a enamorar de una «utopía ecuménica» que abrazase a los sabios de toda tendencia y a los hombres religiosos de toda confesión. Él ha tenido conciencia cristiana de la necesidad de un diálogo universal en época muy temprana. Por eso -y no se extrañe el lector de la hilación causal que aquí se afirma-, su enérgica presencia en el juramento del «jeu de paume» dista mucho de ser fortuita: es su frenesí de amor, lo que le constituye en Padre de la Patria en uno de los momentos más cálidos de la historia de Francia.

Sin embargo, los resultados que iba a obtener no iban a igualar el nivel de sus deseos: el ocaso de Grégoire iba a ser cárdeno -serenidad

4. Monseigneur Grégoire, ancien évêque de Blois, Considérations sur le mariage et sur le divorce adressées aux citoyens d' Haïti, Baudouin Frères, Libraires, Paris 1823, 45-49.

5. No hace falta decir que me refiero a la célebre novela de Gilbert Cesbron, Les saints vont en enfer, Paris 1952, que en su momento cobró popularidad circunstancial por el problema que retrataba. 
desconsolada tras la tormenta- y adverso -sobre todo en su hora final-. Fruto de su paradoja biográfica: por un lado, una ceguera pertinaz para comprender la obediencia; por otro, un fuego de caridad. Un «ethos» de eficacia maquiavélica en pugna con un «pathos» pío y fraterno. Obrar excesivo el suyo -no cabe duda-; pero los escritos salidos de su pluma abundan en desconcertante sabiduría. En la cumbre de la edad Grégoire podía recordar su compromiso llevado «de tout coeur» por más de 40 años dedicados a la noble lucha contra la esclavitud y en pro del afianzamiento y progreso de la civilización en el paisaje de las colonias francesas del Caribe. "Amenazas, persecuciones, calumnias, libelos me han sido dedicados con prodigalidad: porque aquí abajo jamás se ataca a los opresores, jamás se defiende a los oprimidos impunemente. La recompensa por las buenas acciones corresponde a otro orden de cosas que se sitúa más allá de los confines de la vida. Séame permitido rememorar un hecho innegable: durante muchos años he permanecido solo en la brecha, mientras el miedo amordazaba a pretendidos filósofos que embozando su pereza bajo el nombre de prudencia tan sólo se lanzaron a la arena jactándose de bravura cuando ya no existía peligro alguno» ${ }^{6}$.

\section{LA TRILOGÍA REVOLUCIONARIA SOBRE EL HORIZONTE CARIBEÑO}

Ya amaneció la libertad, piensa, sobre el horizonte de Haití; pero esa libertad vendría a nublarse e, incluso, a oscurecerse con las negruras de una loca borrachera si no se garantiza su permanencia inamisible: «Una Constitución, unas leyes sabias son necesarias; son también, sin embargo, insuficientes para el logro definitivo de una libertad plena. El edificio social se arruina pronto si se prescinde del apoyo de la religión, de las virtudes, de las luces, del trabajo» ${ }^{7}$.

«Liberté», «Egalité» y «Fraternité» -como las tres Gracias- aparecen en la doctrina de Grégoire abrazadas, interpenetradas como en recíproca inmanencia, como dimensiones inseparables de la encarnación definitiva de las luces. La «Fraternité» es cristiana: la "Liberté» y la «Egalité» también. Para Grégoire dista mucho de ser indiferente -desde el punto de vista cristiano- la proclamación de estos tres miembros del trinomio revolucionario.

6. Grégoire, ancien évêque de Blois, Épître aux Hä̈tiens, Imprimerie du Gouvernement, Port-au-Prince, 6 mars 1827, an 24e. de l'Independence, 2.

7. Ibidem, 3 . 
Al servicio de la «Liberté» se empeñó Grégoire en compromisos pastorales inspirados por la «Fraternité»: "Yo he hecho sentir la necesidad urgente de establecer un seminario para formar un clero nacional cuyas acciones y discursos, en constante armonía con la religión y la libertad, sean un ejemplo viviente en medio de un pueblo que tiene la ventaja de ser simultáneamente cristiano y republicano. Yo he recomendado sin cesar el cumplimiento de los deberes religiosos ${ }^{8}$. Ser cristiano y republicano podría interpretarse en analogía con el afán hoy en boga, que conjuga inseparablemente cristianismo y democracia. La república garantiza la «Egalité» y la «Liberté» -y con ella, las libertades modernas-. La religión garantiza la «Fraternité». No se puede, por tanto, ser republicano -hijo de la Revolución- sin ser cristiano: «Yo he estigmatizado el concubinato exportado a América por los europeos, plaga infecta y vergonzosa que es todavía entre vosotros una fuente de escándalos, a cuya extirpación deben colaborar -mediante el ejemplo de sus uniones legítimas- los hombres que, constituidos en dignidad, están por eso mismo más estrictamente obligados a ser modelos y a rendir homenaje a la majestad de las costumbres»?.

Podía también recordar el anciano Grégoire sus exhortaciones a la paz de las familias - al mutuo respeto de los cónyuges, a la veneración por parte de los hijos hacia sus padres-. Podía evocar la igualdad, tantas veces tematizada en sus discursos. Igualdad la más radical, entrelazada con la Fraternidad. Y la Fraternidad, universal: aquella que hace sentirse hermanos a todos los hombres de cualquier raza, color, lengua y cultura. A todos los hombres de cualquier religión: «la obligación que tenemos por ser católicos de acoger con entrañas de caridad a los hermanos que yerran, sin aceptar por eso su error». Podía aducir el esfuerzo en pro de la educación. En la república de Haití, los resultados intelectuales florecían muy por encima de la escasa ufanía moral: «Yo desería una vez más a los republicanos un temple de carácter ajeno al orgullo fatuo y al servilismo lisonjero. Libre de afanes de trepar -tan propio de ciertas gentes en Francia, que se limitan a calificar tamaño defecto simplemente de "faiblesse" $\rightarrow "$.

Haití se acercaba ya a las Bodas de Plata de su independencia: con régimen republicano, establecida ya una red comercial prometedora, la joven nación disfrutaba aún de precario reconocimiento en el foro
8. Ibidem, 3.
9. Ibidem.
10. Ibidem, 4 . 
internacional. Por el momento sólo Portugal tenía representante diplomático en Puerto Príncipe. Por lo que a la Iglesia toca, Haití había recibido obispos constitucionales en 1797 ordenados por los obispos franceses reunidos en el Concilio de París. Obispos constitucionales consagrados por obispos constitucionales: Grégoire llevaba la batuta con una libertad tan generosa como excesiva. Haití tuvo de ese modo -en analogía con la Madre Patria- la experiencia de una Constitución Civil del Clero.

Un obrar tan resuelto requiere una verdad de fondo o, al menos, una "species veri". Un título colorado, pero convincente. Para Grégoire fue suficiente título el planctus que se elevaba desde las Indias Occidentales clamando -ya dos siglos- por una jerarquía propia capaz de sintonizar con el alma de aquellas gentes ${ }^{11}$. Grégoire escuchaba la voz del pueblo y la interpretaba como voz de conciencia: así se embocaba sin vacilación por el sendero de la revolución religiosa desaforada. Y con él sus otros compañeros -obispos constitucionales-: ordenaron obispos -que tenían temple evangélico forjado según las fuentes de los tres primeros siglos de la Iglesia- y se los enviaron a Haití haciéndose las cuentas más generosas para el futuro ${ }^{12}$ :

\section{LA Fraternité}

La «Fraternité» es cristiana, pero su interpretación es de signo jansenista inconfundible. En opinión de P. Pisani, "Gregoire es uno de los hombres que han hecho más daño a Francia. En el momento en que parecía que se extinguía el incendio del cisma constitucional, él lo re-encendió y lo atizó durante siete años; hasta su muerte él siguió soplando sobre las cenizas recién apagadas. En esta ardorosa pugna recurrió sin escrúpulos a las armas más desleales - con tal de triunfar y comprometer a quienes le contradecían- propagando calumnias, acreditando historias ridículas y haciendo que quienes se fiaban de él participasen de sus prejuicios y rencores» ${ }^{13}$. Y sin embargo, el propio Pisani, que le dedica un juicio tan severo, se rinde ante la evidencia de un

11. Cfr. Anónimo, Planctus Indorum, s.d., de la segunda mitad del XVIII en Perú. Actualmente prepara una edición del Planctus, precedida por un erudito estudio de introducción el Dr. José María Navarro.

12. Cfr. Épître des évêques réunis à Paris aux pasteurs et aux fidèles des colonies françaises, passim.

13. P. PISANI, Grégoire (Henri), DTC, VI deuxième partie, col.1862. 
talante generoso, víctima de sus sueños proféticos y del romanticismo impulsivo que le consagraba como líder generacional. Grégoire-que tronaba en pro y en revancha de los trabajadores de la gleba invitando a los hijos de la Patria a fecundar aradas y surcos con la sangre de los reyes- no era menos exigente consigo mismo. Los temperamentos coléricos e impulsivos, nacidos para hacer avanzar los tiempos, no deberían ser juzgados por quienes carecen de toda inspiración poética. Y Grégoire era un poeta. Su Éloge de la poésie había merecido el lauro de la Academia de Nancy. Era la primera vez que se ceñía la frente, a sus 23 años. Aunque más que un poeta era un retórico. Con "pectus» enardecedor, concitador, imprudente. La retórica de Grégoire es por igual utópica y desmedida: no todas sus expresiones caben dentro del sentido común. Ahora bien, ¿̇no había publicado Saint Cyran la Question royale ofreciendo 34 argumentos en favor del suicidio para salvar la vida del soberano? Aquel mítico director de conciencias en los albores del jansenismo ponía las bases de un talante profundamente psicologista, penetrante y agudo, romántico y entregado a la utopía hasta la negación del sentido común.

Grégoire siempre negó ser jansenista: porque le jansenisme est un fantosme y quienes son del "parti» han aborrecido siempre de etiquetas confesionales. Pero si la «Fraternitè» revolucionaria es algo, eso es jansenismo -clima espiritual de la revolución, germen espiritual del «gauchisme»-.

De ahí, su perseverancia y su piedad sincera, su exigente cumplimiento de las prácticas de devoción y su culta sensibilidad teológica. Todo, como en los días más brillantes del Port Royal de la Mère Angélique. «En la Biblioteca del Arsenal -refiere Pisani- se conservan unos pequeños cuadernos manuscritos que iluminan más de lo que se pudiera suponer lo que fue la vida interior de Grégoire. Copiados y vueltos a copiar año tras año, contienen una especie de calendario de sus devociones personales: aniversarios de su bautismo, de su ordenación, de su consagración episcopal, de la muerte de sus padres; fiestas de los santos de su particular devoción -los patronos de Lorena, los de la diócesis de Blois; invocaciones a San Gregorio -senador de Autun antes de ser obispo de Langres-, a los santos y santas de raza negra y a todos los apóstoles de los negros. (...) Viene luego su reglamento de vida espiritual: ejercicios espirituales cada año, retiro mensual, examen semanal haciendo balance de los exámenes de conciencia diarios; en fin, las prácticas a observar durante los tiempos de penitencia y en las cuatro témporas. Y cada noche, «tras el primer sueño» interrumpía su reposo, abandonaba 
el lecho y recitando el versículo del salmo 118: Media nocte surgebam ad confitendum tibi, comenzaba una larga oración nocturna» ${ }^{14}$.

Como es de ley, transmitía a los demás lo que era norma de su vida. El Manuel de Pieté, que preparó para los negros y mestizos de Haití, lleva en su frontispicio una proclamación de igualdad -tomada del Sirácida 33, 10- que amasa en unidad el común origen de los hombres y su dignidad efímera: Todos los hombres ha sido tomados del mismo barro $y$ de la misma tierra de la que Adán fue formado. "Yo me atrevo a decir -explica- que este Manual no es más que un suplemento a los demás libros de piedad que se ponen entre las manos de los fieles. No queda uno, por tanto, dispensado de procurarse las Sagradas Escrituras, que son la palabra del mismo Dios -explicada e interpretada por la Iglesia-, la Imitación de Cristo, los libros que contienen las prácticas para la confesión y la comunión, el oficio divino, las preces de la Misa y las oraciones de la mañana y de la tarde». Es decir un devocionario completo para formar con cristiana pulcritud a la ciudadanía. Y continúa: «La más sublime de estas plegarias es la Oración Dominical que hemos aprendido de la misma boca de Jesucristo. ¡Oh qué admirable es su comienzo: Padre Nuestro, que estás en el Cielo! Estas pocas palabras bastan para destruir toda pretensión de orgullo que quisiera establecer diferencias entre los hijos de la misma familia. Aquel que es la verdad misma proclama que somos hijos del mismo Padre. La naturaleza y la religión no reconocen la nobleza del color ni tampoco la del nacimiento. Dios no tiene acepción de personass. Y luego, para reforzar el tenor de sus palabras, exhorta -sorprendentemente para quienes no conozcan el clima espiritual del jansenismo revolucionario-: «Leed la hermosa homilía que el Cardenal Chiaramonti, hoy Su Santidad el papa Pío VII, dirigía el día de Navidad de 1797 al pueblo de Imola, de donde a la sazón era obispo. Mirad con qué ternura les mostraba el feliz acuerdo que reina entre el Evangelio y la libertad política. ¡Qué edificante y qué consolador saber que estas verdades han sido proclamadas por los sucesores de San Pedro, por los jefes de esta religión santa, la única fundada por Jesucristo, la única verdadera, de la que vosotros tenéis la suerte inestimable de ser miembros! ! $)^{15}$.

El precepto del Amor que el Apóstol S. Juan recomienda - el que no ama a su hermano a quien ve, ¿cómo podrá amar a Dios a quien no ve?- $\mathrm{o}$

14. P. PISANI, l.c.

15. Monseigneur Grégoire, Manuel de Piété, à l'usage des hommes de couleur et des noirs, Baudouin Frères, Libraires/Aimé Comte, Paris, Juillet 1818, 2-5. 
que el Evangelio mismo proclama como nota del auténtico discípulo de Cristo -lo que hiciéreis a uno de éstos mis humildes hermanos a Mi me lo hicisteis. Lo que dejásteis de hacer con estos mis humildes hermanos conmigo dejásteis de hacerlo- es doctrina principalísima repetida por Grégoire. La expone acomodada a la inteligencia de los ciudadanos de Haiti: "Un autor ha dicho que Dios no juzga de nuestro amor sino por el resultado de aquel que hayamos tenido a nuestros semejantes. Cualquiera que fuese la cuna de un hombre, su país, su religión, su color, vosotros tenéis derecho a su amor y él tiene derecho al vuestro; y si él está encenagado en el vicio o en el error, llorad sus errores, reconducidle con dulzura -si es posible- a la virtud y a la verdad; pero descubrid siempre en él a un hermano a quien es necesario amar» ${ }^{16}$.

No nos engañemos, sin embargo. Grégoire no pierde su compás: hijo del Evangelio e hijo de la Revolución. Cara y envés de la única moneda de curso legal. «El que fue ciudadano cardenal Chiaramonti es hoy el papa Pio VII» ${ }^{17}$. Y todavía más claro, formulado como un apotegma pastoral: «Un mal ciudadano jamás será un buen cristiano; mientras que un cristiano virtuoso será siempre un digno ciudadano» ${ }^{18}$. ¡Ciudadano! Bien se entiende: el viejo término había cobrado nuevo significado y producido connotaciones de identidad a partir de la Revolución.

Y ¿qué decir de las cofradías? Ellas habían jugado un papel admirable durante la Revolución -sobre todo en la época de la Convención y del Terror-; también habían jugado su papel más tarde, conservando en el seno de los hogares franceses la fe católica y la piedad tradicional. No es fácil saber hasta qué punto Grégoire era capaz de valorar esta función desempeñada por las humildes asociaciones cristianas: tantas veces ocurre que los contemporáneos no reparan en realidades demasiado acostumbradas o en actividades insignificantes. Actividades hondas bajo fenómeno insignificante. El anciano obispo constitucional contempla con justeza: «En diversos lugares se han establecido asociaciones o cofradías bajo las advocaciones de los santos. Además se ha introducido la costumbre de ir en peregrinación a ciertas iglesias; esto puede ser bueno y útil, aunque es más fácil inscribirse en una cofradía o ir en peregrinación que corregirse de un vicio o adquirir una virtud. Cuando S. Jerónimo habla de los que iban a visitar la Tierra Santa, decía con razón: lo laudable no es haber estado en Jerusalén, sino haber vivido santamente en

16. Ibidem, 18-19.

17. Ibidem, 5.

18. Ibidem, 20. 
Jerusalén; porque ¿para qué pueden servir los actos exteriores, si quienes los hacen siguen inclinados a los vicios, a la impureza, a la embriaguez, a la cólera, a la venganza, al orgullo, a la avaricia? (...) Jamás las prácticas exteriores... reemplazarán la caridad, la humildad, el amor del prójimo. Toda práctica que subsiste con los vicios es ilusoria y para nada sirve sino para mecerse en el error. (...) Sed santos, nos dice Jesucristo. La santidad por tanto no es imposible puesto que Dios la exige de nosotros. Quien dice cristiano, dice santo» ${ }^{19}$.

\section{LA SANTIDAD COMO PLATAFORMA DE IGUALDAD}

La santidad, a la que todos somos llamados. Puede decirse que durante siglos ha sido olvidada en la predicación al pueblo numeroso -a la massa christiana - esta teología dogmática, espiritual y práctica que a todos se dirige: en Él nos eligió antes de la constitución del mundo para que fuésemos santos e inmaculados en su presencia por el amor... (Ef 1, 4).

$\mathrm{El}$ anciano obispo de Blois sorprende por sus principios que revelan un alma dotada de lúcida intuición. Ferviente admirador del Apóstol de las Gentes sintoniza con el núcleo de la teología paulina con altura excepcional -excepcional, digo, habida cuenta del momento histórico que le tocó vivir-. "Cuando se dice que debemos imitar a los santos, no está dicho todo. San Juan Bautista y muchos otros se han retirado al desierto para vivir separados del mundo. En esto adoramos las disposiciones de la Providencia, que conduce a sus elegidos por diferentes caminos, algunas veces extraordinarios; pero ella (la Providencia) no exige lo mismo de vosotros. Vosotros no estáis todos llamados al sacerdocio, como tampoco lo estáis a la magistratura o al estado militar etc.; pero todos estáis llamados a ser santos. Esta es la vocación general de todos los cristianos. Vosotros no estáis en el caso de derramar vuestra sangre en defensa de la fe, aunque deberíais estar dispuestos a hacerlo, si Dios os pidiera este sacrificio; pero cada uno en su estado puede ser mártir de la humildad, de la mansedumbre, de la caridad, de la paciencia para soportar las penas de la vida $»^{20}$. Y enseguida proclama con convencimiento: «Para mejor confundir la tibieza, los pretextos y los excesos de los malos cristianos, ha querido Dios que hubiera santos en todos los países y en todas las profesiones honestas. Ellos han tenido las mismas

19. Ibidem, 59-61.

20. Manuel de Piété, 58-59. 
pasiones que nosotros, los mismos obstáculos... Los santos han llegado al cielo por el camino del sufrimiento; no esperéis obtenerlo por otra vía que la que Jesucristo nos ha trazado y que los santos han seguido ${ }^{21}$. Y por fin subraya con fuerza poniendo a todos ante su responsabilidad: «Diréis vosotros: ¡eran santos!...; y ¿vosotros, qué pretendéis? El último lugar del cielo está reservado para un santo. Rezar a los santos es útil, pero imitarlos es indispensable» ${ }^{22}$.

Quien mucho exige, honra a quienes reciben la invitación a mayor exigencia. Quien mucho exige demuestra amar con caridad cabal. Parece indiscutible que el antiguo obispo de Blois profesaba un amor sincero y recio a las gentes de color, a los negros y mestizos, a los desheredados y marginados, a los esclavos, personalmente o constituídos en sociedad, tanto en África como en América. No le conocería bien quien le negase mezquinamente esta aureola venerable, que fue suya hasta que murió en olor de multitudes.

Grégoire tenía corazón y se le notaba. Distaba mucho de carecer de delicadeza. Percibía el carácter sagrado de los valores «virginidad» y «amor esponsal». "La Escritura Santa -escribe- pone de relieve las ventajas espirituales de la virginidad. Tomando una carne como la nuestra, Jesucristo quiso nacer de una Virgen que es la primera y más santa de las criaturas; la Iglesia celebra los triunfos de las vírgenes cristianas, si bien son muy pocas las personas llamadas al celibato. La gran mayoría de las personas tiene vocación matrimonial» ${ }^{23}$. La vocation au mariage. El tenor con que se expresa revela una sensibilidad y un talento selectos. Esos términos podrían contextuarse a final del siglo XX.

Grégoire jamás hubiera admitido la infidelidad sacerdotal que se olvida del celibato. Tuvo siempre en máxima veneración el carácter sacerdotal que adornaba su alma de obispo y de pastor.

No resulta fácil dedicar a una persona así la etiqueta de revolucionario sanguinario y cruel. Acaso el enjuiciamiento histórico de Grégoire está llamado a atenuarse facilitando el respeto ante una postura que, cuando el siglo XX concluye, resulta más comprensible ${ }^{24}$.

21. Ibidem 61-62.

22. Ibidem, 62.

23. M. GréGOIRE, ancien évêque de Blois, Considérations sur le mariage et sur le divorce adressées aux citoyens d'Häiti, Baudouin Frères, Libraires, Paris 1823, 6-7.

24. Un ejemplo de reivindicación de su memoria es el sereno artículo de Bernard Plongeron, Grégoire (Henri-Baptiste) en R. Aubert (dir.), Dictionnaire d'Histoire et de Géographie Ecclesiastiques, XXII (1988) cols. 60-72. 


\section{DEBILIDADES DE UN TALANTE REVOLUCIONARIO}

Existen personas con bravura de carácter, pero con grandeza de corazón. Recogen cosecha de agradecimientos. Grégoire pertenece a este número de personalidades. Fue muy querido. Él vivió en el corazón de Francia durante los años de máximo paroxismo revolucionario y siguió viviendo en su Patria, retirado de la política del gobierno, hasta adentrarse en los años románticos. Él mismo fue un romántico. Tenía un carácter impulsivo, apasionado, retórico hasta la brillantez, con desbordamientos arrebatados -furibundas hipérboles, que la opinión pública de la nobleza y de la burguesía, jamás le perdonó-. Grégoire no fue nunca envidioso -pienso-, ni perteneció a ese número de franceses que hacen opción de superioridad con respecto a lo ultrapirenaico; la opinión que Grégoire dedica a España fue siempre generosa: su admiración hacia Bartolomé de Las Casas en quien veía un precursor, corre pareja con el reconocimiento de la noble conducta española, que siempre dedicó a los esclavos en el Nuevo Mundo un tratamiento de mesura católica -por encima de cualquier otro país, incluso de Francia-. Nunca entendió la Inquisición: le pareció un tribunal feroz, adversario de las libertades, que sojuzgaba el genio de un país luminoso, abierto geográficamente a todos los mares.

Quien conoce la psicología humana, reconoce en qué consiste el adolecer de los corazones que hacen solemne profesión de fraternidad. De ahí nacía el talante hipersensible de Grégoire cuando se sentía con derecho a ser incuestionablemente amado: «Sea como sea -escribe a los ciudadanos de Haití en 1827-, el compromiso que me imponía mi afecto hacia vosotros y vuestra confianza ha concluído. Ha concluido, sí, porque 76 años -más bien agitados- pesan ya sobre mi cabeza y asedian mi existencia. Un déspota del último siglo, Federico de Prusia, comparaba los hombres a los limones: se exprime el jugo y luego se tira la peladura. Pues bien, se dice que uno de vuestros funcionarios, refeririéndose a mí, expresaba la misma idea, aunque fuese en otros términos. - $H a$ concluido, porque mis fuerzas físicas son ya muy débiles por el exceso de trabajos, por las persecuciones que en una larga carrera, y sobre todo desde 1814 hasta el momento actual, me han atormentado sin cesar. Puedo citar, además, franceses por cuyas venas también corre sangre africana, los cuales sin duda por acrecentar o consolidar el crédito de que gozan ante la autoridad gubernativa, han desplegado contra mí un furor propio de energúmenos. Que el cielo los perdone» ${ }^{25}$. 
Cuando el pueblo de Haití leyó estas palabras dadas a la luz por la imprenta gubernamental de Puerto Príncipe, se llenaron de dolor. Nunca se supo quién dijo en el Parlamento haitiano palabras en desdoro del anciano obispo constitucional, mirado como un Padre de la Patria haitiana. Por aquellos años se pasaba fácilmente del abrazo a la calumnia, del beso de Lamourette al terror de la Convención. Fue así muchas veces en aquel comienzo decimonónico. Y así fue también aquella época en el Nuevo Mundo, allende los mares.

«La guerra de España - se ha podido escribir- ha sido la más injusta de cuantas Napoleón pudo hacer; pero lo maravilloso es que el mismo golpe que oprime a España hace libre a América. Europa tan sólo se preocupa de la violencia hecha a Madrid, y resulta que todo el Nuevo Mundo aplaude a esta guerra que el Antiguo condena. A cada batalla que se libra en Castilla, en Burgos, Somosierra, contra España, surge una república independiente a la otra parte del océano, en Chile, Perú o México. Una justicia superior estalla, porque hacían falta tres cosas: primero que España recibiese su castigo por la dureza que desplegó en América; segundo que este castigo la regenerase; en tercer lugar que sus colonias sometidas se transformasen en estados libres. Y todo esto se cumplió por la misma mano, en la empresa que se considera con razón la más inicua del Imperio» ${ }^{26}$. No sólo allende el océano se oían gritos de júbilo cantando la independencia; en 1820 publicaba Juan Antonio Llorente, bajo significativo pseudónimo, los Discursos sobre una constitución religiosa, considerada como parte de la civil nacional. Su autor, un americano. En ellos se proponía una Constitución Civil del Clero más desgarrada y violenta que la que provocó tan graves conflictos en la Francia revolucionaria. «He pensado -dice el autor en el prólogo- que su publicación podría ser útil a los habitantes de América; porque según van los negocios de España, no es temeridad presumir que los de Venezuela, y los del Río de la Plata, los de Chile y los de otros puntos, arriben a consolidar la independencia que apetecen y que ya gozan en parte. Si esto se verificase, podrían los americanos sacar grandes ventajas de adoptar los principios que se indican en el proyecto ${ }^{27}$.

Lo que distingue a Grégoire, hijo de la revolución y padre de la $\mathrm{Pa}-$ tria francesa, es sobre todo la «Fraternité». La «Liberté» es el germen del

26. Edgard QUINET, Le cristianisme et la Révolution Française, Fayard, Paris 1984, 259.

27. Juan Antonio Llorente, Discursos sobre una Constitución Civil Religiosa considerada como parte de la Civil Nacional. Su Autor un Americano. Los da á luz D. ------- Doctor en Sagrados Cánones, Paris 1820, Prólogo. 
liberalismo. La «Egalité» es el germen de la democracia. La «Fraternité» -inspirada en el ideal cristiano y elaborada mediante fermentos jansenistas, como clima espiritual de la Revolución- es el germen perdurable de los romanticismos revolucionarios decimonónicos, y más todavía de los de nuestra época. Fraternidad de sueños utópicos que está en el comienzo del primer izquierdismo de la modernidad, estrictamente tal. De este izquierdismo es representante Henri Baptiste Grégoire. 